\title{
CONSUMO DE CAPIM-ELEFANTE COM DIFERENTES IDADES FORNECIDO PARA VACAS LEITEIRAS*
}

\author{
INTAKE OF ELEPHANT-GRASS WITH DIFFERENT AGES OFFERED TO DAIRY COWS
}

Soares, J.P.G. ${ }^{1}$, F. Deresz ${ }^{2}$, A.K.D. Salman ${ }^{4}$, L.J.M. Aroeira ${ }^{2}$, A.D. Oliveira ${ }^{5}$, R.S. Verneque ${ }^{2}$ e T.T. Berchielli ${ }^{3}$

${ }^{1}$ Embrapa Agrobiologia. BR 465-Km 7. Seropédica-RJ. CEP 23851-970. Brasil. jpsoares@cnpab.embrapa.br ${ }^{2}$ Embrapa Gado de Leite. Rua Eugênio do Nascimento, n. 610. CEP 36038-330. Brasil. laroeira@cnpgl.embrapa.br; deresz@cnpgl.embrapa.br; rsverneq@cnpgl.embrapa.br ${ }^{3}$ Departamento de Zootecnia da FCAV/UNESP. Jaboticabal. Via de Acesso Prof. Paulo Donato Castellane, s/n. Jaboticabal, SP. CEP 14884-900. Brasil. ttberchi@fcav.unesp.br

${ }^{4}$ Embrapa Rondônia. BR 364-Km 5,5. CP 406. Porto Velho, RO. CEP 78900-970. Brasil. Correspondência: aksalman@cpafro.embrapa.br

${ }^{5}$ Departamento de Ciências Ambientais. Instituto de Floresta. UFRural RJ. BR 465-Km 7. Seropédica-RJ. CEP 23890-000. Brasil. alexsandrado@yahoo.com.br

\section{PALAVRAS CHAVE ADICIONAIS}

Conteúdo ruminal. Enchimento físico. Esvaziamento ruminal. FDN.

\section{RESUMO}

O capim-elefante com 30,45 e 60 dias de idade foi avaliado por meio do monitoramento das características nutricionais do capim e do consumo de MS (CMS) e de FDN (CFDN) por vacas mestiças lactantes em um experimento em quadrado latino $3 \times 3$ em que as sub-parcelas foram os horários de esvaziamento ruminal: $0,2,4$ e $6 \mathrm{~h}$ após a refeição. A composição química e a digestibilidade in vitro da MS e o conteúdo ruminal variaram em relação à idade do capim. As médias (em kg/vaca/ dia) do CMS e do CFDN do capim cortado com 30 dias $(8,0$ e 5,3$)$ foram inferiores em relação àquelas do capim com $45(10,0$ e 6,6) e 60 dias $(11,0$ e 7,3$)$. O conteúdo ruminal máximo ocorreu nos horários de 4:22, 3:55 e 3:49 h após o oferecimento do capim cortado com 30,45 e 60 dias, respectivamente. $O$ enchimento físico do rúmen não limitou o consumo do capim-elefante, o qual pode ter sido afetado pelo maior teor de umidade do capim cortado com 30 dias.

* Parte da Tese de Doutorado do primeiro autor na FCAV/UNESP-Jaboticabal, financiada pela FAPESP.

Recibido: 16-5-07. Aceptado: 17-5-07.

\section{AdDitiOnAL KEYWORDS}

Ruminal content. Rumen fill. Rumen evacuation. NDF.

\section{SUMMARY}

The 30, 45 and 60 day-old elephant grasses were evaluated by monitoring their nutritional profile and DM (DMI) and NDF (NDFI) intake by crossbred lactating cows in a $3 \times 3$ Latin square trial, where the split-plots were the rumen evacuation times: 0 , 2, 4 and $6 \mathrm{~h}$ after meal. Chemical composition, in vitro dry matter digestibility and ruminal content ranged with grass age. Means (in $\mathrm{kg} / \mathrm{cow} /$ day) of DMI and NDFI of 30 day-old grass (8.0 and 5.3) were lower than those of grasses with 45 days (10.0 and 6.6) and 60 days (11.0 and 7.3). The maximum of rumen fill was observed at 4:22, 3:55 and 3:49 hours after feeding for treatments with 30,45 and 60 day-old elephant grass, respectively. Rumen fill did not limit the DMI and NDFI of elephant grass, but the dry matter intake of 30 day-old grass may be affected by the wet content.

\section{INTRODUÇÃO}

O consumo é o primeiro passo no processo de conversão do alimento em tecidos e produtos de origem animal porque determina o nível de nutrientes ingeridos 
que são digestíveis e metabolizáveis. No entanto, vários fatores difíceis de serem separados e que estão relacionados ao animal, ao alimento e ao ambiente estão envolvidos com o controle do consumo. De acordo com Mertens (1994), o apetite é uma função da demanda de energia, a qual é determinada pelo potencial genético e o estado fisiológico do animal; logo, dietas que apresentam níveis elevados de energia têm seu consumo determinado pelo atendimento das exigências nutricionais do animal e dietas com baixos níveis energéticos têm como principal fator limitante a capacidade física de ingestão ou de enchimento ruminal. O teor de fibra em detergente neutro (FDN) é um fator que está relacionado com o espaço ocupado pelo alimento no rúmen, sendo tendência atual expressar a capacidade diária de enchimento ruminal em unidades de FDN (Van Soest, 1994). A utilização de forrageiras de baixa qualidade, ou seja, com teores superiores a $60 \%$ de FDN e com teores menores de $6 \%$ de
PB, em condições de pastejo ou de corte, proporciona menor taxa de passagem de partículas, o que acarreta aumento do enchimento do rúmen (Forbes, 1995), além da redução do consumo de matéria seca (Chilibroste et al., 2000).

Como as características químicas das forrageiras tropicais se alteram com a idade da planta, o presente trabalho objetivou avaliar o capim-elefante cortado com 30,45 e 60 dias de idade por meio do monitoramento das características nutricionais do capim, do consumo de MS e de FDN, bem como do conteúdo e do enchimento físico do rúmen de vacas mestiças em lactação.

\section{MATERIAL E MÉTODOS}

O experimento foi conduzido em uma área de 4,5 ha de Latossolo VermelhoAmarelo formada com capim-elefante (Pennisetum purpureum Schum. cv. Napier) manejada em sistema de corte por faixas para obtenção de forragem com 30, 45 e 60

Tabela I. Composição química (\% da MS) e consumo de matéria seca (CMS) e de fibra em detergente neutro (CFDN) do capim-elefante com 30, 45 e 60 dias de idade. (Chemical composition (\% of MS), dry mater (CMS) and neutral detergent fiber (CFDN) intake of elephantgrass with 30,45 and 60 days of age).

\begin{tabular}{|c|c|c|c|c|c|}
\hline \multicolumn{6}{|c|}{ Capim elefante } \\
\hline & 30 dias & 45 dias & 60 dias & EPM & CV (\%) \\
\hline \multicolumn{6}{|l|}{ Composição } \\
\hline MS & 12,82 & 15,95 & 18,25 & 1,23 & 19,40 \\
\hline PB & $11,37^{a}$ & $10,49^{a b}$ & $9,09^{b}$ & 1,14 & 9,00 \\
\hline FDN & $62,99^{b}$ & $65,50^{\mathrm{ab}}$ & $70,12^{a}$ & 2,12 & 2,51 \\
\hline FDA & 32,65 & 33,17 & 35,79 & 1,30 & 17,50 \\
\hline DIVMS (\%) & $58,70^{\mathrm{b}}$ & $57,71^{\mathrm{ab}}$ & $55,16^{\mathrm{b}}$ & 2,03 & 4,70 \\
\hline \multicolumn{6}{|l|}{ Consumo } \\
\hline CMS (kg/dia) & $8,03^{b}$ & $10,00^{a}$ & $11,02^{\mathrm{a}}$ & 1,53 & 24,60 \\
\hline CMS (\% PV) & $1,54^{b}$ & $1,96^{a}$ & $2,12^{\mathrm{a}}$ & 0,56 & 15,91 \\
\hline CFDN (kg/dia) & $5,29^{c}$ & $6,57^{b}$ & $7,31^{a}$ & 1,15 & 24,60 \\
\hline CFDN (\% PV) & $1,02^{c}$ & $1,29^{b}$ & $1,41^{\mathrm{a}}$ & 0,49 & 15,91 \\
\hline \multicolumn{6}{|c|}{$\begin{array}{l}\text { DIVMS: Digestibilidade in vitro da matéria seca; PV: Peso vivo; CV: Coeficiente de variação; EPM: Erro } \\
\text { padrão da média. } \\
\text { Na linha, } a>b>c(p<0,05) \text { pelo teste de Newman-Keuls. }\end{array}$} \\
\hline
\end{tabular}

Archivos de zootecnia vol. 58, núm. 222, p. 298. 


\section{CONSUMO CAPIM-ELEFANTE POR VACASLEITEIRAS}

dias de idade. Foram utilizadas nove vacas mestiças 7/8 Holandês x Zebu canuladas no rúmen com peso médio de $520 \mathrm{~kg}$ e produção média diária de $13,5 \mathrm{~kg}$ de leite. O capim elefante foi fornecido picado $(3-4 \mathrm{~cm}) \mathrm{em}$ quantidade suficiente para manter sobras de $10-15 \%$. O consumo diário foi medido em comedores automáticos tipo CalanGates ${ }^{\circledR}$. O experimento foi dividido em três períodos de avaliação de 30 dias cada. Os esvaziamentos do rúmen foram realizados nos horários de 0, 2, 4 e 6 horas após as refeições. As amostragens de conteúdo ruminal foram realizadas segundo Chilibroste et al. (2000) e Dado e Allen (1995). As amostras do capim-elefante picado e do conteúdo ruminal sólido foram analisadas para matéria seca (MS), proteína bruta (PB), fibra em detergente neutro (FDN) e ácido (FDA) (Silva e Queiroz, 2002). A digestibilidade in vitro da matéria seca (DIVMS) foi determinada pelo método de Tilley e Terry (1963). O experimento foi em parcelas subdivididas com os tratamentos na parcela distribuídos em Quadrado Latino (3x3) repetido três vezes no tempo. Nas sub-parcelas incluíram-se os quatros horários de esvaziamento ruminal. Para as análises estatísticas utilizou-se o procedimento GLM(SAS, 1990) e a comparação múltipla entre médias foi realizada usando o teste Student Newman Keuls (SNK) no nível de 5\% de probabilidade. Considerando o efeito quantitativo da sub-parcela (horário), quando este foi significativo isoladamente ou em interação, procedeu-se a análise de regressão para avaliar o efeito de horário sobre a variável em estudo pelo procedimento REG do SAS (SAS, 1990).

\section{RESULTADOSEDISCUSSÃO}

Os resultados de composição química, digestibilidade in vitro da matéria seca e consumo do capim-elefante com 30, 45 e 60 dias de idade são apresentados na tabela I. Como esperado, os teores de PB reduziram, os de FDN aumentaram e a DIVMS reduziu com o avançar da idade do capim elefante. Com relação ao consumo, não há uma razão clara para que o consumo de MS do capimelefante cortado com 30 dias de idade tenha sido menor do que aqueles observados para os capins com 45 e 60 dias. É possível que o teor de MS tenha influenciado o consumo. O consumo de FDN (CFDN) também aumentou com a idade do capim.

Por análise de regressão dos diferentes horários de esvaziamento em função dos conteúdos de FDN no rúmen geraram-se as seguintes equações para os capins com 30 , 40 e 60 dias, respectivamente:

$$
\begin{aligned}
& y=4,8 x^{2}+1,8 x-0,21\left(R^{2}=83,7 \%\right) ; \\
& y=5,3 x^{2}+1,9 x-0,25\left(R^{2}=91,7 \%\right) e \\
& y=5,8 x^{2}+1,4 x-0,19\left(R^{2}=89,8 \%\right) .
\end{aligned}
$$

Considerando essas equações, o menor consumo de FDN do capim cortado com 30 dias também não pôde ser explicado pelo o enchimento físico por conteúdo de FDN, o qual só ocorreu 4 h20 após a refeição quando a capacidade máxima do rúmen foi atingida (7,40 kg de FDN). Comportamento semelhante foi observado para o capim com 45 dias cujo consumo de FDN foi de $6,60 \mathrm{~kg} /$ vaca/dia e o conteúdo máximo no rúmen $(7,62 \mathrm{~kg}$ de FDN) só ocorreu às 3 h55 horas pós-refeição. Por outro lado, o capim-elefante cortado aos 60 dias de idade apresentou o consumo de $7,31 \mathrm{~kg}$ de FDN/vaca/dia e a capacidade máxima de enchimento ruminal dos animais ocorreu com 7,57 kg de FDN e 3 h50 pós-refeição. Isto mostra que a quantidade de FDN presente no rúmen não foi o fator que determinou a parada de ingestão dos animais visto que o enchimento físico ruminal ocorreu sempre em maiores quantidades de FDN do que aquela consumida.

\section{CONCLUSÕES}

O consumo de FDN do capim-elefante aumentou com a idade e com o teor de FDN do capim. O maior teor de umidade do capim elefante com 30 dias de idade pode ter limitado o consumo do mesmo. O enchimento 
SOARES, DERESZ, SALMAN, AROEIRA, OLIVEIRA, VERNEQUE E BERCHIELLI

físico ruminal avaliado pelo consumo de MS não ocorreu em função exclusivamente do teor de FDN do capim-elefante cortado com 30,45 e 60 dias de idade. Outros fatores

\section{BIBLIOGRAFIA}

Chilibroste, P., S. Tamminga, H. Boer, M.J. Gibb and G. den Dikken. 2000. Duration of regrowth of ryegrass (Lolium perenne) effects on grazing behaviour, intake, rumen fill and fermentation of lactating cows. J. Dairy Sci., 83: 984-995.

Dado, R.G. and M.S. Allen. 1995. Intake limitations, feeding behaviour, and rumen function of cows challenged with rumen fill from dietary fiber or inert bulk. J. Dairy Sci., 78: 118-133.

Forbes, J.M. 1995. Voluntary food intake and diet selection in farm animals. CAB International. Walingford. $532 \mathrm{p}$.

Mertens, D.R. 1994. Regulation of forage intake. In: devem ser considerados além do conteúdo ruminal de MS e FDN e da composição química dos alimentos para o entendimento do controle do enchimento físico ruminal.

Fahey Jr., D.C. Forage quality, evaluation and utilization. American Society of Agronomy. Madison. p. 450-492.

SAS. 1990. User's guide: basics and statistics. SAS Inst. Inc. Cary, NC. 956 p.

Silva, D.J. e A.C. Queiroz. 2002. Análise de alimentos (métodos químicos e biológicos). UFV. Viçosa. $245 \mathrm{p}$.

Tilley, J.M.A. and R.A. Terry. 1963. A two stage technique for the in vitro digestion of forage crops. J. Br. Grass. Soc., 18: 104.

Van Soest, P.J. 1994. Nutritional ecology of the ruminant. Cornell University Press. Ithaca. $476 \mathrm{p}$. 